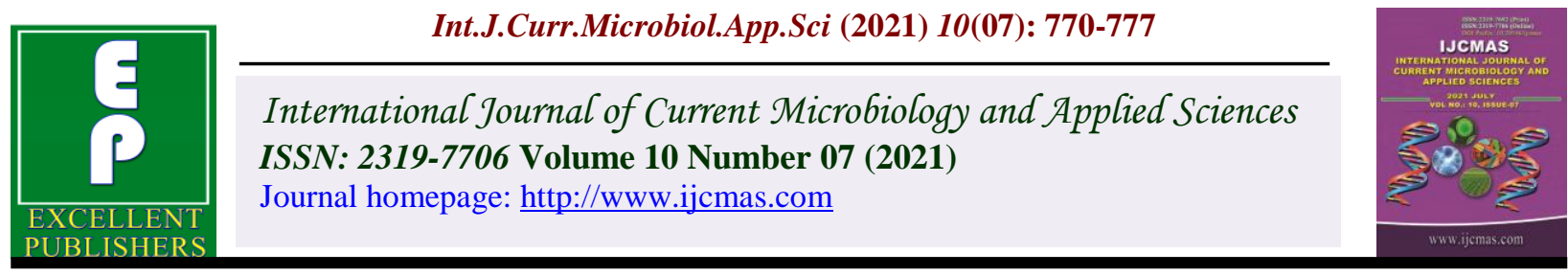

Original Research Article

https://doi.org/10.20546/ijcmas.2021.1007.084

\title{
Effects of Deltamethrin on Behaviour Response and Haematology Profile of Air Breathing Fish Clarias batrachus (Linn.)
}

\author{
Mala Kumari* and M. K. Chandan \\ Department of Zoology, R. K. college, Madhubani, LNM University, Darbhanga, India \\ *Corresponding author
}

Keywords

Clarias batrachus, deltamethrin, DLC (Differential leucocytes count), heamatology

Article Info

\section{Accepted:}

20 June 2021

Available Online:

10 July 2021

\section{A B S T R A C T}

The current investigation was undertaken to study the haematological profile alterations induced by chronic (30 days) exposure of the fish Clarias batrachus (Linn.) to a sublethal concentrations $(0.015 \mathrm{ppm})$ of synthetic pyrethroid, deltamethrin. At haematological levels various parameters, such as $\mathrm{Hb}, \mathrm{RBC}, \mathrm{WBC}$ decreases while in DLC, Neutrophil, Monocytes and Eosinophil values increase. So, it is suggested that more suitable to culture at water pesticides deltamethrin concentration of $<0.015 \mathrm{mg} / \mathrm{l}$ for optimum growth performance and survival rate than other water conditions.

\section{Introduction}

The environment is contaminated with different kinds of pollutants. Pesticides are one of such anthropogenic pollutants which play an important role in controlling different types of pests that cause damage to the crops and to improve agricultural production. Insecticides, fungicides and herbicides constitute the major source of potential environmental hazards not only to birds, fish, and other animals but also to humans when they become a part of food chains (Khan et $a l .$, 2012). Indiscriminate use of pesticides on crops causes serious environmental hazards affecting aquatic fauna. Unfortunately, most of the pesticides are not biodegradable and tend to persist for years together in the environment. Haematological studies on fishes have assumed greater significance due to the increasing emphasis on pisciculture and greater awareness of the pollution of natural freshwater resources in the tropics. Such studies have generally been used as an effective and sensitive index to monitor physiological and pathological changes in fishes (Summarwar and Verma, 2012). The fish, Clarias batrachus, locally known as "Mangur", having the presence of suprabranchial accessory respiratory organs, an air-breathing teleost and deltamethrin were selected for present study. Deltamethrin belongs to a group of pesticides called synthetic pyrethroids. Deltamethrin is known to be toxic to fish and various other aquatic organisms (Mittal, 1994). 


\section{Materials and Methods}

The air-breathing teleost Clarias batrachus procured live from the local fish market were washed with $0.1 \% \mathrm{KMnO}_{4}$ solution to remove dermal infection if any. Healthy fish of average length $(10-12 \mathrm{~cm})$ and weight (21-25 g) were acclimated for 15 days to laboratory conditions. The fish were fed with chopped goat liver every day adlibitum. Running tap water was used in all the experiments and the fish were adjusted to natural photoperiod and ambient temperature. No aeration was done.

Static acute bioassays were performed to determine $\mathrm{LC}_{50}$ values of deltamethrin for 24 , 48, 72 and 96 hours following the methods of APHA, AWWA \& WPCF (1985). The $\mathrm{LC}_{50}$ values for these periods were $1.5 \mathrm{ppm}, 0.85$ ppm, $0.45 \mathrm{ppm}$ and $0.15 \mathrm{ppm}$ respectively. The sub-lethal concentration was determined following the formula of Hart et al., (1945). Twenty acclimated fish were exposed to a sub-lethal concentration (0.015 ppm) of deltamethrin for 30 days. Side by side same number of fish as that of experimental one was maintained as the control group. At the end of exposure period the fish were anaesthetized with 1:4000 MS 222 (tricane, methane, sulfonate, sandoz) for two minutes. On $30^{\text {th }}$ day blood samples was extracted from the caudal dorsal of the test fish and were then processed for estimation of haemoglobin, RBC, WBC, Lymphocytes, neutrophil, monocytes, basophil, eosinophil and determination of PCV (packed cell volume) as method (Akela et al., 1996; Shrivastav, 1979).

\section{Results and Discussion}

\section{Fish Behavioral Response}

The control fish shows a tendency to remain at the bottom of the aquarium with little disturbance. However, mortalities were removed immediately, and behavioural abnormalities were assessed at these regular intervals using a modified behavioural protocol checklist (Klesius et al., 2000). Scores were assigned daily to individual fish in the experiment and were based on the following scoring system: 0 , no observed changes in behaviour; 1, swimming abnormally, lethargic or unresponsive, changes in skin coloration; 2, hyperactive or excitable, rapid operculation; 3, death. Mean behaviour scores were calculated per replicate treatment.

Just after introduction to test solution fishes showed increased swimming, surfacing and hyperactivity. Restlessness, rapid surfacing, peeling of skin and colour fading were prominent after $24 \mathrm{hr}$ exposure. After $48 \mathrm{hr}$ exposure the fishes showed slightly reduced activity and gradual increase in colour fading. Gill adhesion and a thin film of mucous were noticed on gills, operculum and general body surface at this stage. After $72 \mathrm{hr}$ exposure increased surfacing and gulping of air was observed. At this stage fishes showed loss of balance and jerky movements during swimming. The school formation, a characteristic of this fish, was found weakened in test animals as compared to controls at this stage. After $96 \mathrm{hr}$ ulceration on trunk, base of caudal and pectoral fins were prominent in 95\% of the animals. A thick film of mucous on whole body and gills was observed in almost all test fishes. Test fishes lost their natural colouration and. Loss of equilibrium before death is a symptom shown all the test fish. Similar steps of behavioral response also found in sublethal dose of deltamethrin i.e. $0.015 \mathrm{ppm}$ for 30 days of duration of experiment.

\section{Haematological studies}

From Table: -1 .) it is quite clear that $\mathrm{Hb}$ in control value is $12.56 \pm 0.06 \mathrm{gm} / \mathrm{dl}$ which is decreases under Deltamethrin as $7.79 \pm 0.11$ 
$\mathrm{gm} / \mathrm{dl}$ and showed highly significant $(\mathrm{P}<0.001)$. Similarly the value of $\mathrm{RBC}$ decreases under Deltamethrin at $4.68 \pm 0.08$ in contrast to control value $6.79 \pm 0.01$. the decreased value under treatment showed highly significant $(\mathrm{P}<0.001)$ (Table: -1 , Figure:-1). values of Neutrophil, Monocytes, Eosinophil is increasing under treatment groups such as $16.1 \pm 0.04,8 \pm 0.03$ and $1.4 \pm$ 0.02 in compare to control value such as $7.74 \pm$ $2.01,5 \pm 0.05,1.1 \pm 0.03$. Neutrophils are highly significant $(\mathrm{P}<\quad 0.001)$, while Eosinophils showed significant $(\mathrm{P}<0.01)$ and Basophil showed non significant $(\mathrm{P}<0.05)$. In DLC (Differential leucocytes count) the values of Lymphocytes and Basophil are decreases under treatment groups. In control to values are $66.43 \pm 242$ and $1.1 \pm 0.02$ while under treatment the values decreases as $48 \pm$ 0.02 and $1.3 \pm 0.02$. the Lymphocytes showed significant $(\mathrm{P}<0.01)$ while Basophil showed non significant $(\mathrm{P}<0.05)$. Similarly $\mathrm{PCV}$ (Packed Cell Volume) also decreases under treatment group as $12.01 \pm 0.03$ compared to control group as $35.95 \pm 0.06$. It showed significant $(\mathrm{P}<0.01)$ (Table:-1, Figure:-2).

At haematological levels various parameters, such as $\mathrm{Hb}, \mathrm{RBC}, \mathrm{WBC}$ decreases while in DLC, Neutrophil, Monocytes and Eosinophil values increases while Lymphocytes and PC value decreases. The increase or decrease value showed either significant, highly significant or non-significant. It causes various diseases Erythropoesis, anaemia, Leucocytopaemia, Neutropaemia, Lymphopaemia, Eosinophilia and Erythropaemia.

In the present study, certain deformities and unusual swimming patterns were found in fish exposed to $0.015 \mathrm{mg} / \mathrm{L}$ and above concentrations of deltamethrin. The responses recorded for the fish in this study are similar to those reported by other authors under various stress conditions (Paul and Banerjee, 1996; Rani et al., 1997; Palanivelu et al.,
2005; Lata et al., 2008). Behavioural responses of fish to most toxicants are the most sensitive indicators of potential toxic effects (EIFAC, 1983). Acute toxic effect mercuric chloride was observed on zebrafish by Vutukuru, Basani K. (2013); Pathak P. \& Anand, (2020). The toxic effects of ammonium chloride fertilizer on fish $C$. batrachus, Sangeeta et al., (2020). The toxic effects of surfactant, dodecyl dimethyl benzyl ammonium chloride (1227) on larval locomotors of zebra fish was observed by Yanan, et al., (2015). It is, therefore, conclude that the toxicity of the pesticide deltamethrin depend upon a number of physical, chemical and biological factors. Each of which may be used as a tool for pesticides toxicity to fish.

\section{Haematological study}

\section{Haemoglobin}

The present findings were in conformity of Raizada and Gupta, (1982) has explained a decrease in RBC number and haemoglobin was observed in the fish Trichogaster fasciatus after exposure to the fungicide RH216. In C. batrachus, haemoglobin content decreased from 15.34 to $10.30 \mathrm{~g} \%$ in $96 \mathrm{hr}$ with 10 ppm of Rogor. Muthalagi (2006) has explained different circulation of sewage of the $\mathrm{Hb}$ to the fish C. mirgala.

Again Arjun et al., (2009) has explained the $\mathrm{Hb}$ treatment under chromium exposure to the fish $C$. batrachus and found similar decrease in the level of $\mathrm{Hb}$ and $\mathrm{Hb}$ treatment under chromium showed highly significant $(\mathrm{P}<0.001)$. Similar results of $\mathrm{Hb}$ decline has been also reported by Revathi et al., (2003), Shipra et al., (2005), Anwar and Choudhary (2009) has been reported in rat also. Again Pratibha and Kumar (2013) has explained $\mathrm{Hb}$ treatment under mercury chloride and showed similar decrease level results in $\mathrm{Hb}$ and also showed $\mathrm{Hb}$ is highly significant $(\mathrm{P}<0.001)$. 


\section{RBC}

The present study showed also conformity with Heteropneustes fossilis, the pesticide malathion resulted in a decrease in RBC count from $6,400,000$ to $3,460,000 / \mathrm{cm}^{*}$ in $96 \mathrm{hr}$ at $7.6 \mathrm{ppm}$ (Mishra and Srivastava, 1983). In fishes, Muthalagi (2006) has found similar nature of decrease under sewage treatment to the fish C. mrigala. Again Arjun et al., (2009) has found similar nature of decline in RBC under the treatment of chromium to the fish $C$. batrachus. Very recently Pratibha and Kumar (2013) has found similar decline nature of RBC under the treatment of mercury chloride to the fish $H$. fossilis (Bloch). The present findings, i.e. decrease in RBC level was close conformity with fish and mammals studies.

On the basis of above facts that the chemicals disrupts in form of synthesis machinery because of Glycolysis inhibition. Further it has been explained that toxicants could destiny the blood cells leading to significant decrease.
Shipra et al., (2005) clearly explained the decline of RBC, which reduces $\mathrm{Hb}$. Very recently Muthulagi (2006) showed similar significant reduction under domestic sewage while Pratibha and Kumar (2013) has showed similar decline in RBC under the treatment of mercury chloride to the fish $H$. fossilis (Bloch).

\section{WBC}

During present study the WBC decreases are close conformity with various workers, under the treatment of fertilizers, pesticides, alkaloids to fishes or mammals. In fishes Muthalagi (2006) has been reported similar decrease of WBC under domestic sewage to the fish C. mrigala. Recently Arjun (2010) has explained similar decrease of WBC under chromium exposure to Clarias batrachus. The present findings are conformity with various mammals, such as rat, rabbit etc. under the exposure of metals, pesticides, alkaloids etc.

Table.1 Showing the effects of Deltamethrin on Hb, RBC, WBC, DLC, PCV of Clarias batrachus.

\begin{tabular}{|c|c|c|c|}
\hline \multicolumn{2}{|c|}{ Variable } & \multirow{2}{*}{\multicolumn{2}{|c|}{$\begin{array}{c}\text { Deltamethrin (96 hrs) exposure } \\
0.015 \mathrm{mg} / \mathrm{l}\end{array}$}} \\
\hline Parameter & Control & & \\
\hline Blood Hb (gm/l) & $12.56 \pm 0.06$ & $7.49 \pm 0.12$ & $* * *$ \\
\hline TEC(RBC) $\left(\times 10^{6} \mu \mathrm{l}\right)$ & $6.79 \pm 0.01$ & $4.68 \pm 0.08$ & $* * *$ \\
\hline \multicolumn{4}{|l|}{ DLC (WBC) (\% values) } \\
\hline Neutrophil & $7.74 \pm 2.04$ & $16.2 \pm 0.04$ & *** \\
\hline Lymphocytes & $66.43 \pm 2.42$ & $48.0 \pm 0.02$ & ** \\
\hline Monocytes & $5.0 \pm 0.03$ & $8.0 \pm 0.03$ & $*$ \\
\hline Eosinophil & $2.0 \pm 0.03$ & $3.0 \pm 0.02$ & ** \\
\hline Basophil & $1.1 \pm 0.02$ & $1.2 \pm 0.02$ & $*$ \\
\hline PC (\% values) & $35.95 \pm 0.06$ & $12.02 \pm 0.03$ & ** \\
\hline
\end{tabular}

Values are mean \pm SE of 5 individual observations:-

$* \mathrm{P}<0.5 \quad$ Non Significant, $* * \mathrm{P}<0.01 \quad$ Significant, $* * * \mathrm{P}<0.001 \quad$ Highly Significant 
Fig.1 Showing the effect of Deltamethrin on Hb, RBC, WBC in Clarias batrachus (96 hrs) ***P $<0.001$.

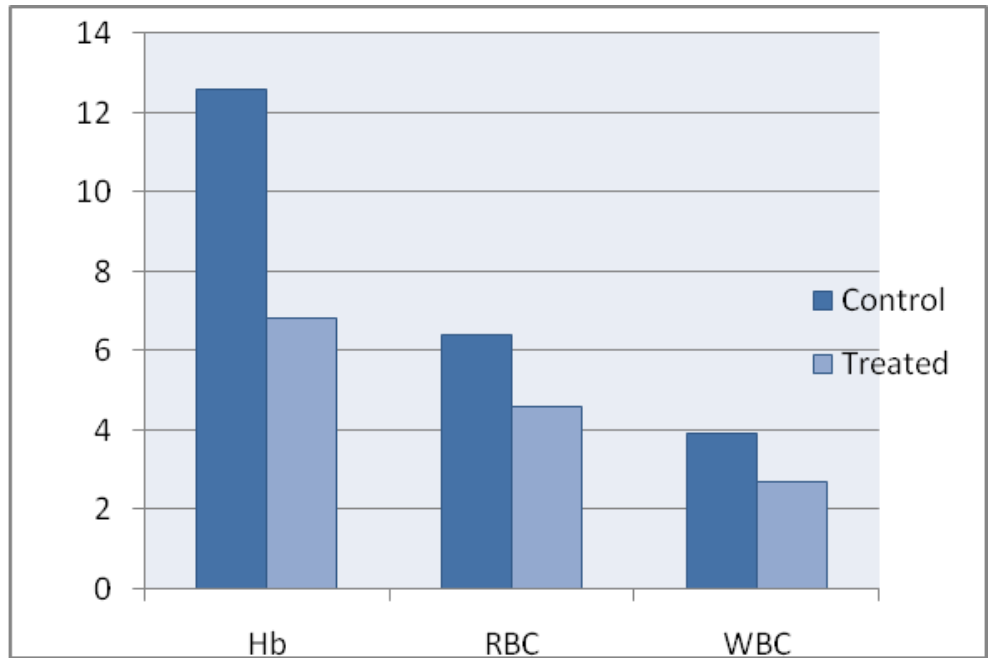

PARAMETERS

Fig.2 Showing the effect of Deltamethrin on Neutrophil, Monocytes, Basophil in Clarias batrachus $(96 \mathrm{hrs}) * \mathrm{P}<0.05, * * * \mathrm{P}<0.001$.

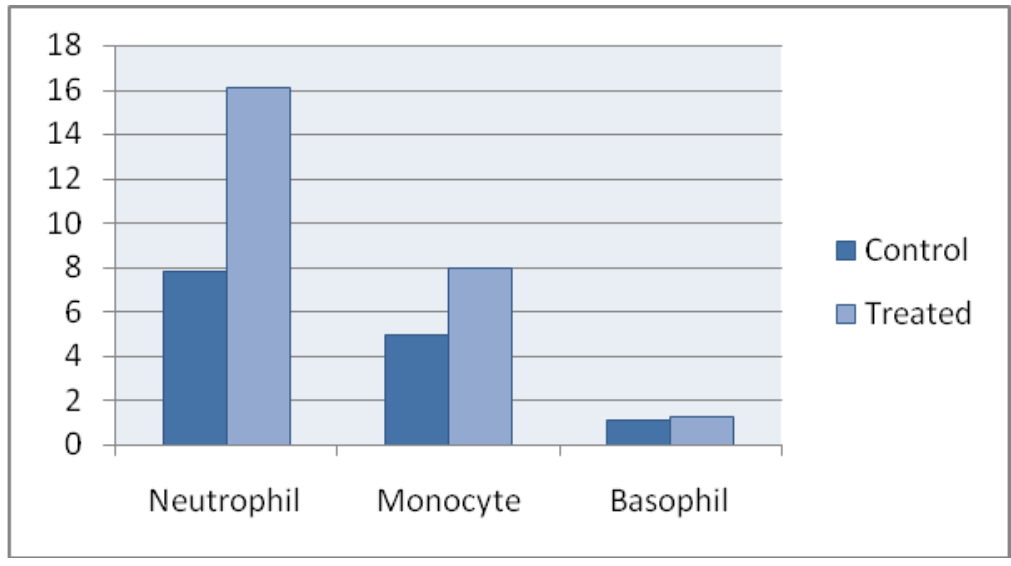

PARAMETERS 
Fig.3 Showing the effect of Deltamethrin on Lymphocytes, Eosinophil, PCV, in Clarias batrachus (96 hrs) ** $\mathrm{P}<0.01$.

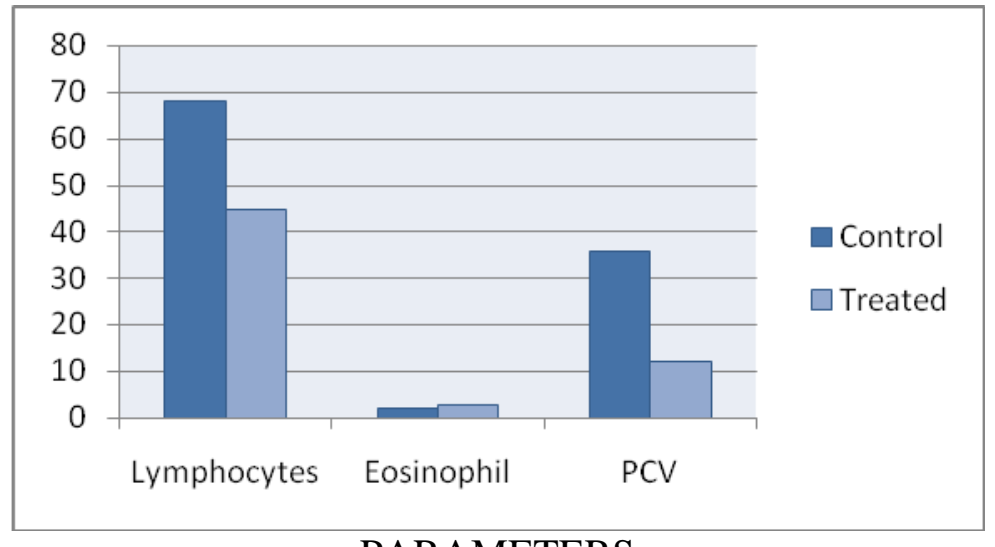

PARAMETERS

Initial increase in the WBC count was might be the result of direct stimulation of immunological defence due to the presence of toxic substance or may be associated with induced tissue damage. The present findings are conformity with Revathi et al., (2003), Shipra et al., (2005), Anwar and Choudhary (2009). Pratibha and Kumar (2013) has explained exposure of mercury chloride to the fish $H$. fossilis. These workers has been found same decrease in WBC in Rat under various exposure of sewage, alkaloids etc. On the basis of above facts it is quite clear that WBC plays a very important role in the defense mechanism of body. A decrease in WBC count is termed as leucopaemia. The common cause of this includes blood poisoning in which the body literally runs out of WBC.

\section{DLC}

During present study under DLC Neutrophil, Monocytes and Esnophil increase while Lymphocytes, Basophil decreases. The increase and decrease values are in close conformity with Muthalagi (2006), Arjun (2010) and Pratibha and Kumar (2011) under various exposure of sewage, chromium and mercury chloride to the fishes.

While Revathi et al., (2003), Shipra et The reduction in RBC count and Hb are often al.,(2005), Anwar \& Choudhary (2009) has found same levels of decrease or increase in Rat. $\mathrm{CCl}_{4}$ (injected at 0.03 and $0.06 \mathrm{ml} / 100 \mathrm{~g}$ body weight at intervals of 3 days) caused considerable lymphocytosis; i.e., within 6 days, lymphocytes increased from 33 to $72 \%$ (Sharma and Gupta, 1982).

Neutropaemia might be under exposure of Diammonium phosphate under 20 days Lymphopaemia in 20 days exposure to $\mathrm{Di}$ ammonium phosphate increased secretion of Adraline (Table:-2, Fig.-2 \& 3).

\section{PVC}

The present study (Table-1, Fig.-3) is conformity with Muthalagi (2006), Arjun (2010) and Pratibha (2013) in fish water fishes under exposure of sewage, chromium as well as cadmium chloride. Similarly Revathi et al., (2003) has explained similar decrease in PC, $\mathrm{MCV}, \mathrm{MCH}$ and $\mathrm{MCHC}$ with increase in tannery effluent concentrations. Similar results was obtained by Arjun under exposure of chromium to Clarias batrachus. Pratibha and Kumar (2013) has explained to same decrease of PCV, MCV, MCH and MCHC under the exposure of Cadmium chloride to the fish $H$. fossilis (Bloch). 
accompanied by a decrease in PVC and demonstrates the physiological dysfunction of the haemopoietic system. It could be concluded that Clarias batrachus with average weight $30.0 \pm 4.0 \mathrm{~g}$, were more suitable to culture at water pesticide, Deltamethrin concentration of $<0.015 \mathrm{mg} / \mathrm{l}$ for optimum growth performance and survival rate than other water conditions.

\section{Acknowledgement}

The authors are thankful to the Department of Zoology, R.K. college, Madhubani, LN Mithila University, Darbhanga, Bihar for the provision of laboratory facilities used in this study.

\section{References}

Anwar and Choudhary 2009: Effects of Quinine and Atropine to rat. J. of Natural conservatives Indian, 21(2), pp. 325-329.

Arjun Sah, Roy, D. N. Nutan 2009: Effect of $\mathrm{Hb}$ parameters on chromium to $C$. batrachus. J. of Environ \& Ecoplaning 16 (1), 93-101.

Arjun S. 2010: Effects of chromium on haematological and histopathological parameters, $C$. batrachus. Ph. D. thesis, L.N.M.U., Darbhanga.

EIFAC (European Inland Fisheries Advisory Commission).1973: Water quality criteria for European freshwater fish report on ammonia and inland fisheries. Water Research, 7: 10111022.

Finney D. J. 1978: Statistical methods in biological assay. 3rd ed. London UK: Griffin Press; p. 508.

Goel, K. A., and Maya 1986: Haematological anomalies in Clarius butrachus under the stress of Rogor. Adv. Biosci. 5, 187-192.

Khan, A., Ahmad, L. and Khan, M. Z., 2012.
Hemato-biochemical changes induced by pyrethroid insecticides in avian, fish and mammalian species. Int. J. Agric. Biol. 14: 834-842.

Klesius, P. H., C. A. Shoemaker, and J. J. Evans. 2000: Efficacy of a single and combined Streptococcus iniae isolate vaccine administered by intraperitoneal and intramuscular routes in tilapia (Oreochromis niloticus). Aquaculture 188:237-246.

Lata, S., Sriwastwa,V. M. S., Maurya, J. P. and Chaudhary, S. K. 2008: Urea induced testicular changes in Mystus vittatus. J. Eco. Biol., 23:11- 17.

Mishra, J., and srivastava, A. K. 1983: Malathion-induced haematological and biochemical changes in the Indian catfish, Heteropneustes fossilis. Environ. Res. 30,393-398.

Mittal, P. K., Adak, T. and Sharma, V. P., 1994. Comparative toxicity of certain mosquitocidal compounds to larvivorous fish Poecilia reticulate. Indian. J. Malariol. 31: 43-47.

Muthalgi, S. 2006: Effect of different concentration of sewage on the haematological parameters of $C$. mirgila. Indian J. Eniron. \& Ecoplan 12(2), 409-412.

Palanivelu, V., Vijayavel, K., Ezhilarasi Balasubramanian, S. and Balasubramanian, M. P. 2005: Impact of fertilizer (urea) on oxygen consumption and feeding the freshwater fish Oreochromis mossambicus. Environmental Toxicology and Pharmacology, 19: 351-355.

Palanivelu, V. 1997:.Influence of Cartap and urea on the physiology of fresh water fish Oroechromis mossambicus. University of Madras, Ph. D Thesis.

Paul, V. I. and Banerjee, T. K. 1996: Ammonium sulphate induced stress related alterations in the respiratory 
epithelium of the air breathing organ of the catfish (Heteropneustes fossilis). Journal of Biosciences, 21: 519-526.

Pathak P. \& Anand A K., 2020: Biochemical changes of mercury chloride on blood metabolite level of freshwater fish Heteropneustes fossilis.J. of Emer. Tech. \& Inov. Res., Vol. 7(11).

Pratibha, K. 2013: Haematological \& biochemical effects of mercuric chloride to Heteropneustes fossilis. Ph.D. thesis of L.N.M.U. Darbhanga.

Raizada, M. N., and Gupta, A. 1982: Toxic effect of Rh-2 16 (a systemic fungicide) from total erythrocyte counts (RBC) and haemoglobin $(\mathrm{Hb})$ content of Trichogaster fasciatus. Comp. Physiol. Ecol. 7(1), 29-30.

Rani, E. F, M. Elumalai, M. P. Balasubramanian 1997: The toxicity of mixtures of monocrotophos and ammonium chloride to a freshwater fish Oreochromis mossambicus. Biomedical Lett.,55 : 193-198.

Rewathi, K. M. Yogananda \& K. Kaplarasi 2003: of tannary effluent on the biochemical and haematology of wistar albino rats. Indian J. Environ \& Ecoplan, 7(3):629-632.

Sangeeta \& Anand A K., Jha B. K., 2020:
Toxicity Of Ammonium chloride On Fish bihaviour \& Histopathology Of Air Breathing Fish Clarias batrachus (Linn.), J. of Emer. Tech. \& Inov. Res., Vol. 7(11).

Shipra, Shamra, R. P. Goyal, Geetanjali Chakravaraty \& Anjali Sharma 2005: Orange red, a blend of permitted food colour induced haematological changes in swiss albino mice, 24(2): 99-103.

Sprague, J. B., 1971: Measurement of pollution toxicity to fish. III. Sub lethal effects and 'safe' concentration, Water Res.5: 245- 266.

Summarwar, S. and Verma, S., 2012. Study of selected haematological indices of freshwater fish from Bisalpur reservoir. I.J.Fundament. Appl. Lif. Sci. 2(2): 51-54.

Vutukuru S. S., Basani K. 2013: Acute effects of mercuric chloride on glycogen and protein content of Zebra fish, Daniorerio. J. Environ Biol. 34:277281.

Yanan, W,. Yuan Z., Sun M., and Zhu W. 2015: Exploring the effects of different types of surfactants on zebra fish embryos and larvae. Springer Nature. Sc. Rep. article No. 10107.

\section{How to cite this article:}

Mala Kumari and Chandan, M. K. 2021. Effects of Deltamethrin on Behaviour Response and Haematology Profile of Air Breathing Fish Clarias batrachus (Linn.). Int.J.Curr.Microbiol.App.Sci. 10(07): 770-777. doi: https://doi.org/10.20546/ijcmas.2021.1007.084 